$£ 480000$ would be saved. As segmental phenolic ablation results in fewer recurrences savings would be greater as the number of reoperations would fall: we would recommend that patients with a systemic or arterial disease, which might impair healing, should, however, be treated by doctors.

The treatment chosen for ingrowing toenails should have a low recurrence rate and a reasonable cost. ${ }^{+}$If patients were referred to a suitably trained-state registered-chiropodist for segmental phenolic ablation this ideal might be attained.

1 Sykes P'A. Ingrowing toenails: time for critical appraisal? $7 R$ (Coll Surg Edmb $1986: 31: 300-4$.

2 Murray WR, Bedi BS. The surgical management of ingrowing toenails. $B r$. Surg $1975 ; 62: 409 \cdot 12$

3 Wallace A, W'oodside J, Long J. Ingrowing toenails. I'ulse 1986 July 12: 25-32. + Miller SS. Ingrowing toenails. Br.Med 7 1985;291:91-2.

Accepled 2.March 1988
Malvern, Worcestershire WR143BL M C Colquhoun, MRCP, general practitioner

\section{Use of defibrillators by general practitioners}

\author{
M C Colquhoun
}

Roughly $60 \%$ of deaths from myocardial infarction occur outside hospital and are due to ventricular fibrillation occurring shortly after the onset of symptoms. ' All methods of resuscitation administered outside hospital aim at giving a defibrillatory shock with the minimum delay. In Britain many patients summon a general practitioner during the early stages of myocardial infarction, and evidence suggests that around $5 \%$ of such patients experience a cardiac arrest in the presence of a general practitioner, who is therefore ideally situated to attempt resuscitation..$^{23}$

The proceeds of the 1985 London to Brighton cycle ride enabled the British Heart Foundation to donate 78 defibrillators to general practice. This report describes the impact of these defibrillators and investigates the circumstances in which a British general practitioner. might perform defibrillation. Potential hazards and problems were also investigated.

\section{Patients, methods, and results}

Practices were selected to receive Lifepak -5 defibrillators on the basis of a questionnaire circulated to all general practitioners in Britain, taking account of training, size of practice, distance from hospital, and whether the local ambulance service had defibrillators. All recipients were asked to return a questionnaire every time the machine was used, recording basic data about the patient, the circumstances in which cardiac arrest occurred, initial rhythm, and methods used in the resuscitation attempt. The outcome, final diagnosis, technical problems, and injuries were also recorded. Nil returns were also collected.

Twenty five practices ( 99 doctors) recorded use of the defibrillator; 24 practices ( 100 doctors) recorded no use during the year studied. Fifty three attempts at resuscitation were made; $16(30 \%)$ of the patients reached hospital alive, $10(19 \%)$ were eventually discharged. Success was highest when ventricular fibrillation was the initial rhythm: 32 patients, 12 $(37 \%)$ reaching hospital alive and seven $(22 \%)$ were discharged. When asystole was the initial rhythm results were much poorer: 18 patients, one reaching hospital and subsequently being discharged. The estimated time to reach patients in ventricular fibrillation was 4.8 minutes and in asystole nine minutes, suggesting that those in the second group were suffering the terminal asystole that follows ventricular fibrillation.

Nineteen patients suffered arrests in the presence or immediate vicinity of a general practitioner (table); 13 developed ventricular fibrillation and the remainder were converted to ventricular fibrillation and subsequently defibrillated. Initial success $(68 \%)$ and hospital discharge rate $(47 \%)$ were excellent.
Myocardial infarction was responsible for 44 cardiac 등 arrests, but the following conditions were also re- $\bar{\omega}$ corded once: left atrial myxoma, haemorrhage from $\widetilde{\Phi}$ lymphoma, cerebrovascular accident, aortic stenosis, 을 myocarditis, multiple injuries, and idiopathic ventricular fibrillation.

Outcome of cardiac arrests occurring in the presence or vicinity of a general practitioner

Resuscitation Survival to Discharged

\begin{tabular}{|c|c|c|c|c|}
\hline \multicolumn{5}{|l|}{ Ventricular } \\
\hline Asystole & 3 & 2 & 1 & 1 \\
\hline $\begin{array}{l}\text { Broad complex } \\
\text { tachycardia (with } \\
\text { no output) }\end{array}$ & 2 & 0 & 2 & 1 \\
\hline $\begin{array}{l}\text { Electromechanical } \\
\text { dissociation } \\
\text { Total }\end{array}$ & $\begin{array}{r}1 \\
19\end{array}$ & $\begin{array}{l}0 \\
6\end{array}$ & ${ }_{13}^{1}(68 \%)$ & $9_{9(47 \%)}^{1}$ \\
\hline
\end{tabular}

\section{Comment}

The 25 defibrillators used in the first year after their provision to general practitioners saved 10 lives. The results confirm that a significant number of patients suffer arrest near a general practitioner, who, if suitably trained and equipped, stands an excellent $\mathbb{D}$ chance of saving their life. Such general practitioners $\underset{\vec{P}}{\vec{F}}$ may play an important part in reducing the mortality of myocardial infarction by reaching patients quickly (preferably before the onset of serious arrhythmias) and educating susceptible patients to summon help immediately after the onset of symptoms.

The long term prognosis for such patients is excellent, ${ }^{4}$ suggesting that defibrillators are a sound and cost $\frac{5}{3}$ effective investment. One can be bought for $£ 1350$.

Conditions other than myocardial infarction occur of with sufficient frequency for the general practitioner not to assume automatically that ischaemic heart disease is responsible for all cardiac arrests.

Few technical problems and no serious injuries occurred during resuscitation, in agreement with the findings of Cummings and Eisenberg, who emphasised $N$ the safety of cardiopulmonary resuscitation, a point $N$ that needs emphasis in view of the increasing number of attempts at resuscitation being made in the community.

I thank all doctors who contributed to the survey and all $\stackrel{\mathcal{?}}{+}$ staff of the British Heart Foundation, Professor D G Julian 7 for his invaluable advice, and Hazel Davies of Syntex Cardiovascular for secretarial help.

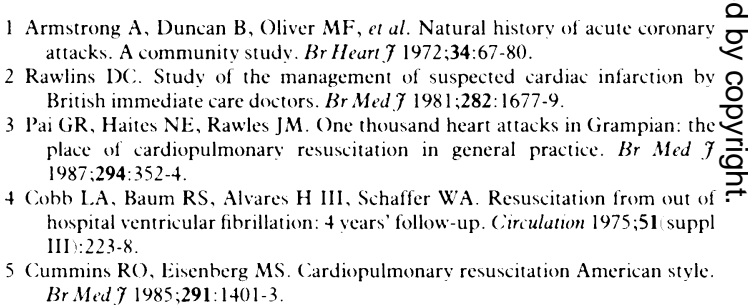

+ Cobb L.A. Baum RS, Alvares H III, Schaffer WA. Resuscitation from out of hospital ventricular fibrillation: 4 vears' follow-up. ('irculation 1975;51 supp III $: 223-8$.

5 Cummins R(), Eisenherg MS. (Cardionulmonary resuscitation American style. BrMed 7 1985;291:1401-3.

Accepted 6 A pril 1988 